\title{
Role of dopamine in non-depressed patients with a history of suicide attempts
}

\author{
W. Pitchot*, M. Hansenne, M. Ansseau \\ Psychiatric Unit, CHU Sart Tilman, B-4000 Liège, Belgium \\ (Received 15 January 2001; revised 26 July 2001; accepted 31 August 2001)
}

\begin{abstract}
Summary - Several data are available about the implication of the dopaminergic system in the control of inwarddirected aggression. Previously, we suggested an involvement of D2-dopaminergic function in the expression of suicidal behavior by demonstrating a smaller growth hormone (GH) response to apomorphine, a dopaminergic agonist, in depressed patients with a history of suicide attempts in comparison to non-attempters. In the present study, in order to test this hypothesis, GH responses to intravenous apomorphine were measured in non-depressed patients with a history of suicide attempts. The study was performed in 17 non-depressed male patients with a score less than 12 on the 17-item HAMD. The patients were subgrouped into suicide attempters $(N=7)$ and non-attempters $(N=10)$. Mean GH peak responses to apomorphine differed significantly between suicide attempters and non-attempters: (mean $\pm S D$ ) for GH peak, $10.4 \pm 8.2 \mathrm{ng} / \mathrm{mL}$ vs $27.3 \pm 13.1 \mathrm{ng} / \mathrm{ml}, \mathrm{F}=9.0, P=0.009$. In conclusion, dopaminergic disturbances seem to play a role in the biology of inward-directed aggression in non-depressed patients. (c) 2001 Éditions scientifiques et médicales Elsevier SAS
\end{abstract}

depression / dopamine / monoamine / suicide

\section{INTRODUCTION}

An extended literature exists concerning the role of serotonin in the biology of suicidal behavior. Few data are available about the possible implication of the dopaminergic system in the control of inward-directed aggression. Postmortem studies have provided conflicting results. Crow et al. [7] reported an increase in homovanillic acid (HVA) concentrations in the hippocampus but not the cortex of suicide victims. Ohmori et al. [14] observed an increase in HVA levels in the frontal cortex of individuals who committed suicide compared to subjects who died due to physical illness. In contrast, Beskow et al. [5] and Arranz et al. [4] did not find any difference in HVA concentration at the level of the cortex of suicided subjects. These results have been confirmed in another study at the level of five other cerebral areas (caudate, putamen, nucleus accumbens, amygdala, hippocampus) [6]. This study demonstrated a decrease in dihydroxyphenylacetic acid (DOPAC) concentrations in the caudate, putamen and nucleus accumbens. The role of dopamine in suicidal patients has also been evaluated in cerebrospinal fluid (CSF) studies. Several studies have reported low HVA levels in depressed patients with a history of suicide attempts compared to controls [8]. Moreover, low CSF HVA levels could be a more reliable index of suicidal behavior than low CSF 5-indroxyindolacetic acid (5-HIAA) [12].

${ }^{*}$ Correspondence and reprints. 
In 1992, we suggested an involvement of D2-dopaminergic function in the expression of suicidal behavior by demonstrating a smaller growth hormone $(\mathrm{GH})$ response to apomorphine, a dopaminergic agonist, in depressed patients with a history of suicide attempts in comparison to non-attempters [15] Recently, we showed that depressed patients who later died by suicide exhibited a significantly lower GH response to apomorphine challenge than depressed patients who never attempted suicide [18] Nevertheless, this measure of impaired dopamine activity in depressed patients could be related to the diagnosis of depression or to certain aspects of symptomatology, in particular motor retardation. In the present study, in order to test this hypothesis, GH responses to subcutaneous injection of apomorphine were measured in nondepressed patients with a history of suicide attempts.

\section{METHODS}

\section{Subjects}

The study was performed in 18 non-depressed male inpatients with a score less than 12 on the 17-item Hamilton depression scale (HAM-D) [10]. This score was mainly due to aspecific symptoms such as psychic and somatic anxiety, insomnia or somatic complaints. All patients had a score less than 1 on the psychomotor retardation item of the HAM-D scale. The DSM-III-R clinical diagnoses of the patients [2] were personality disorder (three cases); anxiety disorder (seven cases), including five panic and two social phobic disorder diagnoses; and adjustment disorder (eight cases). On the basis of a clinical interview, we excluded patients with another current DSM-III-R axis I disorder, and more particularly an affective disorder. The patients were subgrouped into suicide attempters $(N=7$, personality disorder $=2$, anxiety disorder $=3$, adjustment disorder $=2)$ and non-attempters $(N=11$, personality disorder $=1$, anxiety disorder $=4$, adjustment disorder $=5$ ). The two groups did not differ in mean age or weight. These patients were included in another study [16] The apomorphine test was performed after a drug-free period of at least 2 weeks [17]. Moreover, there was no significant difference in washout periods between groups.

Past history of suicide attempt was based on interviews with patients and their family members. We only included suicide attempts with a real intent to die as described by patients. All patients were free of medical illness as evidenced by history, medical examination, electrocardiogram, chest $\mathrm{x}$-ray, electroencephalogram, and routine laboratory tests. Patients with a basal systolic blood pressure less than $100 \mathrm{mmHG}$ were excluded from the study. Moreover, in order to be included, patients had to present a basal $(\mathrm{t} 0) \mathrm{GH}$ level less than $5 \mathrm{ng} / \mathrm{mL}$ before the pharmacological challenge [3]. The exclusion of subjects with basal GH values $>5 \mathrm{ng} / \mathrm{mL}$ was recommended by Laakman [1], who demonstrated that 'presimulator' healthy volunteers responded significantly less to a noradrenergic challenge than healthy volunteers with low basal values. Finally, the protocol was approved by the Ethical Committee of the University of Liège Medical School, and all patients were fully informed of the study and gave their consent.

\section{Neuroendocrine test procedure}

The apomorphine test was performed in all subjects at bedrest after an overnight fast. At 7 a.m, an indwelling catheter was inserted in a forearm vein. Blood samples of $10 \mathrm{~mL}$ were collected at $-20,0,+20,40,60$ and $120 \mathrm{~min}$ after injection at $8 \mathrm{a} . \mathrm{m}$. of apomorphine $0.5 \mathrm{mg}$ diluted in saline to obtain $0.5 \mathrm{~mL}$ subcutaneously.

GH was measured with a double antibody radioimmunoassay [9], with intra-assay and interassay coefficients of variation of, respectively, $13.3 \pm 4.7 \%$ and $14.8 \pm 9.6 \%$ and a detection limit of $0.2 \mathrm{ng} / \mathrm{mL}$.

\section{Data analysis}

$\mathrm{GH}$ responses to apomorphine were measured by $\mathrm{GH}$ peak values following injection. Analyses were performed using absolute $\mathrm{GH}$ values as well as differences related to basal (t0) levels (relative values). Since the correlation between absolute and relative values were very high $(r>0.98)$, only absolute values are reported here. Moreover, since peak and area under the curve values are generally highly correlated $(r>0.97)$, we decided to choose $\mathrm{GH}$ peak values as the measure of maximal hormonal response to apomorphine. The responses of patients with and without a history of suicide attempts were compared by analysis of covariance (ANCOVA) for age. 


\section{RESULTS}

Mean GH peak responses to apomorphine differed significantly between suicide attempters and nonattempters (mean \pm SD): for GH peak, $10.4 \pm 8.2 \mathrm{ng} /$ $\mathrm{mL} \quad$ vs $27.3 \pm 13.1 \mathrm{ng} / \mathrm{mL}, \quad \mathrm{F}=9.0, \quad \mathrm{df}=3, \quad 15$, $P=0.009$.

\section{DISCUSSION}

The results of the present study tend to confirm a specific role for D2-dopaminergic receptors in the biology of inward-directed aggression in non-depressed patients. Indeed, non-depressed patients with a history of suicidal behavior exhibited a significantly lower $\mathrm{GH}$ response to apomorphine challenge than patients who had never attempted suicide. Therefore, a blunted GH response to apomorphine could be considered as a possible 'biological marker' of suicidal behavior.

These results are in agreement with several previous studies assessing dopaminergic activity by measuring CSF dopaminergic metabolites in suicide attempters. Träskman et al. [23] found lower levels of CSF HVA in patients with a history of either violent or nonviolent suicide attempts than in controls. Montgomery and Montgomery [13] and Agren [1] also showed a highly significant relationship between low CSF HVA levels and suicidal behavior, and a weaker correlation with low CSF 5-HIAA levels. In a longitudinal study over a period of 5 years, Roy et al. [20] observed that patients who reattempted suicide during the follow-up had lower CSF HVA levels compared to controls. The predictive value of low CSF HVA concentrations has been confirmed in another longitudinal study over a period of 2 years [24]. More recently, Engtröm et al. [8] confirmed the relationship between CSF HVA levels and suicidality in a large sample of depressed patients. Roy et al. [21] have also found that depressed patients with a history of suicidal behavior exhibited smaller urinary outputs of HVA, DOPAC and total body output of dopamine than patients who never attempted suicide. Moreover, Roy and Pollack [22] demonstrated that urinary measures of the dopaminergic metabolites could be a strong indicator of suicide risk. In contrast, Mann and Malone [12] did not find any association between CSF HVA levels and suicidality in depressed suicide attempters with a high degree of lethality.

All CSF studies which tend to demonstrate an association between low HVA levels and suicidality have been performed in suicide attempters with mood dis- orders. Recently, Engstöm et al. [8] suggested that discrepancies observed between several studies could be explained by the clinical heterogeneity of suicide attempters and that low HVA levels might be markers of depression as such rather than a biological risk factor of suicidal behavior. To our knowledge, our study is one of the first to provide results suggesting a relationship between dopaminergic function, and more specifically D2-receptors, and suicidal behavior in nondepressed patients. Therefore, our results tend to suggest that the association between dopamine and suicidality could be observed in several diagnostic entities.

These results should be taken with caution due to the small sample size. Moreover, a major limitation is that the dopamine-mediated GH response to apomorphine is occurring at the level of the hypothalamus. Regarding the dopaminergic hypothesis of suicidal behavior, we are particularly interested in dopaminergic function in mesocortical and mesolimbic systems, and it is unclear to what extent a hypothalamically-mediated endocrine response is informative about these systems. Another limitation is the lack of specific assessment of a possible lifetime diagnosis of depression that could influence the results.

\section{REFERENCES}

1 Agren H. Life at risk: markers of suicidality in depression. Psychiat Dev 1983; 1 : 87-104.

2 American Psychiatric Association. Diagnostic and statistical manual of mental disorders, 3rd ed. rev. Washington DC: APA; 1987.

3 Ansseau M, Scheyvaerts M, Doumont A, Poirrier R, Legros JJ, Franck G. Concurrent use of REM latency, dexamethasone suppression, clonidine and apomorphine tests as biological markers of endogenous depression. Psychiatry Res 1984 ; 12 : 261-72.

4 Arranz B, Blennow K, Eriksson A, Mansson JE, Marcusson J. Serotonergic, noradrenergic, and dopaminergic measures in suicide brains. Biol Psychiatry $1997 ; 41$ : 1000-9.

5 Beskow J, Gottfries C, Roos B, Winblad B. Determination of monoamine and monoamine metabolites in the human brain: postmortem studies in a group of suicides and in a control group. Acta Psychiatr Scand 1976 ; 53 : 7-20.

6 Bowden C, Cheetham SC, Lowther S, Katona CLE, Crompton MR, Horton RW. Reduced dopamine turnover in the basal ganglia of depressed suicides. Brain Res 1997 ; 769 : 135-40.

7 Crow TJ, Cross AJ, Cooper SJ, et al. Neurotransmitter receptors and monoamine metabolites in the brains of patients with alzheimer-type dementia and depression and suicides. Neuropsychopharmacology $1984 ; 23: 1561-9$.

8 Engström G, Alling C, Blennow K, Regnéll G, TräskmanBendz L. Reduced cerebrospinal HVA concentrations and HVA/ 5-HIAA ratios in suicide attempters. Monoamine metabolites in 120 suicide attempters and 47 controls. Eur Neuropsychopharmacol $1999 ; 9: 399-405$. 
9 Franchimont P. Le dosage radioimmunologique de l'hormone de croissance humaine. Cah Med Lyon 1968 ; 44 : 887-98.

10 Hamilton M. A rating scale for depression. J Neurol Neurosurg Psychiat $1960 ; 23$ : 56-62.

11 Laakmann G. Psychopharmacology and depression research. Berlin: Springer-Verlag; 1990.

12 Mann JJ, Malone KM. Cerebrospinal fluid amines and higherlethality suicide attempts in depressed inpatients. Biol Psychiatry $1997 ; 41: 162-71$.

13 Montgomery SA, Montgomery D. Pharmacological prevention of suicidal behavior. J Affective Disord 1982 ; 4 : 291-8.

14 Ohmori T, Arora RC, Meltzer HY. Serotonergic measures in suicide brain: the concentration of 5-HIAA, HVA, and tryptophan in frontal cortex of suicide victims. Biol Psychiatry $1992 ; 32: 57-71$.

15 Pitchot W, Hansenne, Gonzalez Moreno A, Ansseau M. Suicidal behavior and growth hormone response to apomorphine test. Biol Psychiatry $1992 ; 31: 1213-9$.

16 Pitchot W, Gonzalez Moreno A, Hansenne M, Ansseau M. Growth hormone response to clonidine in nondepressed patients with a history of suicide attempts. Biol Psychiatry 1995; 37 : 201-3.

17 Pitchot W, Hansenne M, Gonzalez Moreno A, Ansseau M. Effect of previous antidepressant therapy on the growth hormone response to apomorphine. Neuropsychobiology 1995b ; $32: 19-22$.
18 Pitchot W, Reggers J, Pinto E, Hansenne, Fuchs S, Pirard S, et al. Reduced dopaminergic activity in depressed suicides. Psychoneuroendocrinology $2001 ; 26: 331-3$.

19 Roy A, Agren A, Pickar D, Linnoila M, Doran A, Cutler N, et al. Reduced CSF concentrations of homovanillic acid and homovanillic acid to 5-hydroxyindolacetic acid ratios in depressed patients: Relationship to suicidal behavior and dexamethasone nonsuppression. Am J Psychiatry $1986 ; 143$ : 1539-45.

20 Roy A, De Jong J, Linnoila M. Cerebrospinal fluid monoamine metabolites and suicidal behavior in depressed patients: a 5-years follow-up study. Arch Gen Psychiatry 1989 ; 46 : 609-12.

21 Roy A, Karoum F, Pollack S. Marked reduction in indexes of dopamine metabolism among patients with depression who attempt suicide. Arch Gen Psychiatry 1992 ; 49 : 447-50.

22 Roy A, Pollack S. Are cerebrospinal fluid or urinary monoamine metabolite measures stronger correlates of suicidal behavior in depression? Neuropsychobiology 1994 ; 29 : 164-7.

23 Träskman L, Asberg M, Bertilsson L, Sjöstrand L. Monoamine metabolites in CSF and suicidal behavior. Arch Gen Psychiatry $1981 ; 38: 631-6$.

24 Träskman-Bendz L, Alling C, Alsén M, Regnéll G, Simonsson P, Öhman R. The role of monoamines in suicidal behavior. Acta Psychiatr Scand 1993 ; 371 (Suppl) : 45-7. 